GA-A22159

$$
\text { CONF-950905--39 }
$$

\title{
A HIGH POWER EXPERIMENTAL TRAVELING WAVE ANTENNA FOR FAST WAVE HEATING AND CURRENT DRIVE IN DIII-D AND RELEVANCE TO ITER
}

by

D.A. PHELPS, H. IKEZI, and C.P. MOELLER

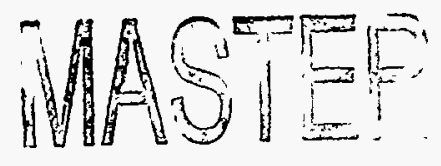

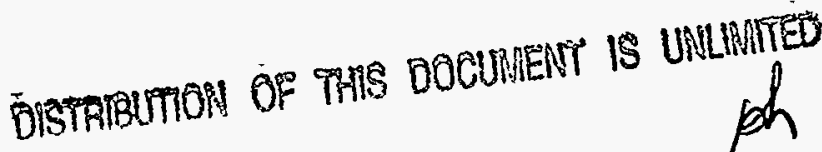




\section{DISCLAIMER}

This report was prepared as an account of work sponsored by an agency of the United States Government. Neither the United States Government nor any agency thereof, nor any of their employees, makes any warranty, express or implied, or assumes any legal liability or responsibility for the accuracy, completeness, or usefulness of any information, apparatus, product, or process disclosed, or represents that its use would not infringe privately owned rights. Reference herein to any specific commercial product, process, or service by trade name, trademark, manufacturer, or otherwise, does not necessarily constitute or imply its endorsement, recommendation, or favoring by the United States Government or any agency thereof. The views and opinions of authors expressed herein do not necessarily state or reflect those of the United States Government or any agency thereof. 


\title{
A HIGH POWER EXPERIMENTAL TRAVELING WAVE ANTENNA FOR FAST WAVE HEATING AND CURRENT DRIVE IN DIII-D AND RELEVANCE TO ITER
}

by

D.A. PHELPS, H. IKEZI, and C.P. MOELLER

This is a preprint of a paper presented at the 16th IEEE/NPSS Symposium on Fusion Engineering, September 30-October 5, 1995, Champaign, Illinois, and to be printed in the Proceedings.

\author{
Work supported by \\ U.S. Department of Energy \\ Contract DE-AC03-89ER51114
}

GENERAL ATOMICS PROJECT 3466 OCTOBER 1995 


\section{DISCLATMER}

Portions of this document may be illegible in electronic image products. Images are produced from the best available original document. 


\title{
A High Power Experimental Traveling Wave Antenna for Fast Wave Heating and Current Drive in DII-D and Relevance to ITER*
}

\author{
D.A. Phelps, H. Ikezi and C.P. Moeller \\ General Atomics \\ P.O. Box 85608 , San Diego, California 92186-9784
}

\section{ABSTRACT}

The impact of a contemplated conversion of the directly driven high power antenna arrays in DIII-D to externally tuned and coupled traveling wave antennas (TWAs) is evaluated based on empirical modeling, computer simulation and low power experiments. A regime of operation is predicted within the TWA passband in which the reflected power from the TWA approaches $0.1 \%$ during ELM-free $\mathrm{H}$-mode. Furthermore, this reflected power does not exceed $1 \%$ and the optimum phase velocity produced by the TWA decreases less than 5\% during ELMs. This resilient operating regime is phase shifted using external tuning stubs, thus providing considerable experimental flexibility. Over $90 \%$ plasma coupling efficiency is achieved by recovering the TWA output power using a novel traveling wave recirculator. Combining the above attributes with efficient plasma coupling even at large antenna-plasma distances and the lack of need for dynamic tuning, TWAs appear to offer great promise for ITER.

\section{INTRODUCTION}

Although an ongoing technical challenge during changing plasma conditions [1-4] the three antenna arrays now in DIII-D can couple power to the plasma within narrow radiation spectra that are established by frequency and certain fixed phases between elements of $0^{\circ}, \pm 90^{\circ}$ and $180^{\circ}$. By operating the two new antennas [5] at $80 \mathrm{MHz}$, and the older antenna [6] at $60 \mathrm{MHz}$, these spectra peak at certain fixed phase velocities suitable for matching on the average to the desired fast magnetosonic wave phase velocities in present DIII-D plasma. However, higher frequencies or arbitrary phase tunability will be needed to match to future higher temperature plasmas.

A phase tunable option to the directly driven antenna is a TWA [7-14], defined as a toroidal array of elements in which power is coupled into and out of the end elements only. The power is carried predominantly in one direction through the array by a structure wave that propagates via inductive and/or mutual coupling between elements. During a pass through the TWA, this structure wave is damped by evanescent coupling to the plasma along the plasma facing surface of the array. If significant, the uncoupled power appearing at the output is recirculated back to the input in traveling wave resonance [7,10,13-14]. By tuning of each element or changing the operating frequency, a continuous and broad range of structure wave phase velocities and local cyclotron resonances (or non-resonant regimes) can be accessed. This includes fast wave current drive (FWCD), profile control, or direct electron heating experiments [15] with a structure wave phase velocity comparable to the electron thermal velocity, as well as heating at harmonics of the ion cyclotron frequency with a phase velocity much faster than the electron thermal velocity. With regard to advanced experimental scenarios in DIII-D and ITER, the TWA can change phase velocity on command to meet different requirements during startup, or track the optimum fast wave phase velocity as plasma electrons are heated $[10,11]$.

Recently, low power externally coupled TWA cold tests [9-11] and experiments in DIII-D [12-14] have successfully validated the optimum conditions for single-pass, or multipass operation. TWAs can couple over $90 \%$ of the input power to the plasma, while maintaining less than a few percent reflected power, and they can maintain a directional phase velocity spectrum with a stable peak phase velocity regardless of changes in plasma conditions. These are major advantages compared to directly driven arrays which must face major control issues [1-3] in accommodating nominal $100 \mu \mathrm{s}$ rise-time edge localized modes (ELMs).

The opportunity now exists to perform high power experiments with the particularly simple to implement TWA structure described herein. Section II describes a generic rf circuit for converting any of the antennas in DIII-D to TWAs and gives low power experimental validation for the important operating features. Section III analyzes single pass coupling from a TWA to plasma. Section IV extends this analysis to multi-pass coupling. Conclusions are given in Section V.

\section{AN RF CIRCUIT FOR TWA CONVERSION OF ANTENNAS IN DWI-D}

Consider the four element antenna that is located inside the DIII-D vessel as sketched in Fig. 1. Each element is effectively a magnetic loop. As described in more detail elsewhere [6], one side of each loop couples power to the plasma. One end is shorted to the antenna housing wall and

\footnotetext{
*Work supported by the U.S. Department of Energy under Contract No. DE-AC03-89ER51114.
} 
the other is connected to transmission line that passes through the DIII-D vessel. Movable stub tuners external to the vessel terminate each of the four transmission lines as shown in Fig. 1. The coupling between elements is a combinaton of mutual coupling $\left(\mathrm{K}_{12}, \mathrm{~K}_{23}, \mathrm{~K}_{34}\right)$ and the identified external coupling inductors. The power flow through this externally coupled and tuned TWA is the same as that defined in the introduction. The rest of the rf circuit in Fig. 1 pertains to recirculation of power through the TWA as discussed in Section. IV.

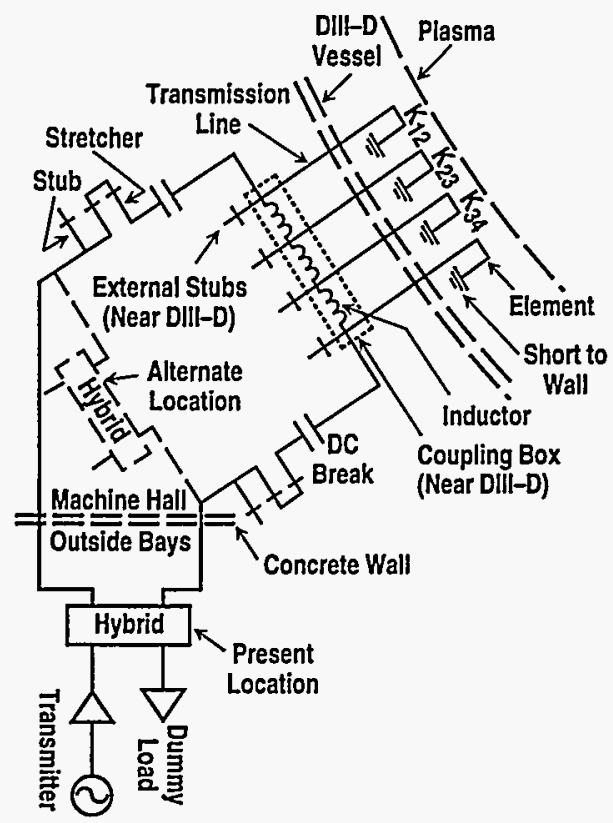

Fig 1. RF Circuit schematic.

Concept validation experiments in DIII-D were conducted at low power using the rf circuit in Fig. 1 (with output terminated) to convert one of the new antennas in DIII-D to a TWA with a bandwidth between the lower and upper cutoff frequencies $[7,8]$ of about $25 \%$ of the midband frequency. Examples of changing plasma conditions and observed TWA behavior are given in Fig. 2. Fig. 2(a) shows the increase in plasma density after the ohmic to $\mathrm{H}$-mode transition. ELMs are observed in the $D_{\alpha}$ emission from the divertor [Fig. 2(b)]. Fig. 2(c) shows the variation in the plasma coupled power (plus ohmic loss). During ELMing $\mathrm{H}$-mode this is around $60 \%$ on the average. Fig. 2(c) demonstrates that the reflected power remains less than a few percent regardless of ELMs, or even plasma disruption and a return to loading in vacuo (i.e., with only ohmic loss). These and other results [12-14] provide the basis for a successful high power TWA experiment in DIII-D. The design of this TWA is described in Sections 3 and 4.

\section{CONVERSION OF THE OLDER ANTENNA TO A TWA FEATURING SINGLE PASS COUPLING TO PLASMA}

A coupled lossy transmission line formalism developed by others [16], that we have found consistent with low power
TWA experiments [13], was used to simulate the TWA illustrated in Fig. 1 and specified by the parameters listed in

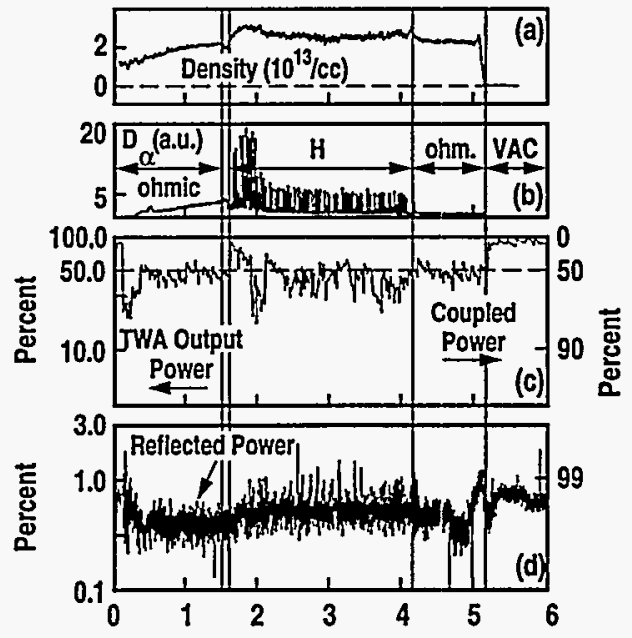

Fig 2. Example of plasma conditions and TWA behavior $\left(\mathrm{B}_{\mathrm{T}}=\right.$ $2.1 \mathrm{~T}, \mathrm{I}_{\mathrm{p}}=650 \mathrm{kA}$, element-separatrix gap $-8 \mathrm{~cm}$ during $\mathrm{H}$-mode).

Table I. The second harmonic TWA passband was selected for study in this paper. This corresponds to two halfwavelengths of electrical length between each element short circuit and the corresponding external tuning stub [10]. At $60 \mathrm{MHz}$ this length is $5 \mathrm{~m}$, which permits installation of the inductor coupling box, tunable stub-shorts and input/output tap points within the same region of space near the DIII-D vessel that is occupied by present transmission line. Moreover, there are existing stub-stretcher tuners within the machine hall to match the input/output tap points, as well as ample room above these tuners for a hybrid directional coupler (refer to Section IV).

Some important features of this TWA are given in Fig. 3. In Fig. 3(a) the phase between elements, $\theta(\omega)$, varies smoothly through midband (at $57 \mathrm{MHz}$, where $\theta=90^{\circ}$ ). The fractional bandwidth for this TWA, $\Delta \omega / \omega=35 \%$, is computed by dividing the bandwidth between the identified $0^{\circ}$ and $180^{\circ}$ cutoffs by the midband frequency. To within $5 \%$ the variation in $\theta(\omega)$, and thereby phase velocity, $v_{\theta}(\omega)$, is independent of resistance for resistive loads less than about $5 \Omega$. This is within the range of plasma loading typically observed during $\mathrm{H}$-mode operation of the older antenna in DIII-D with and without ELMs [17], and explains the observed insensitivity of $\theta$ in low power TWA experiments during ELMing H-modes [12-14].

The output power in Fig. 3(b) is about $50 \%$ for $1.4 \Omega$ per element. This is typical of ohmic loss plus ELMfree $\mathrm{H}$-mode loading of the older antenna. The coupling increases to about $90 \%$ for the $4-5 \Omega$ per element simulated ELM loading.

Fig. 3(c) shows that the simulated TWA exhibits an operating regime at around $60-70^{\circ}$ per element with a remarkable $0.1 \%$ 
Table I

TWA Modeling Parameters for the Older Antenna in DIII-D and Off-line Mock-up

\begin{tabular}{l|l|l|l|l|l|c|c|c}
\hline & $\begin{array}{l}\text { Physical } \\
\text { Parameter }\end{array}$ & \multicolumn{1}{|c|}{$\mathbf{v} / \mathbf{c}$} & $\mathbf{Z}_{\mathbf{0}}(\Omega)$ & $\rho(\Omega / \mathbf{m})$ & $\mathbf{K}_{\mathbf{1 2}}=\mathbf{K}_{\mathbf{3 4}}$ & $\mathbf{K}_{13}$ & $\mathbf{K}_{13}=\mathbf{K}_{\mathbf{2 4}}$ & $\mathbf{K}_{\mathbf{1 4}}$ \\
\hline Element in DIII-D [mockup] & $45[45] \mathrm{cm}$ & $0.52[0.52]$ & $42[35]$ & $0.12[0.12]$ & $0.095[0.07]$ & $0.074[0.065]$ & $0.016[0.007]$ & $0.004[0.002]$ \\
Stripline in DIII-D [mockup] & $34[38]$ & $1[1]$ & $32[32]$ & $0.005[0.005]$ & & & \\
Vac. Coax in DIII-D [mockup] & $75-82\{13]$ & $1[1]$ & $30[40]$ & $0.86[0.02]$ & & & \\
Feedthrough in DIII-D & 12 & 1 & 30 & 0.086 & & & \\
External 6in. EIA Coax. & -900 & 1 & 25 & 0.01 & & & \\
\hline
\end{tabular}
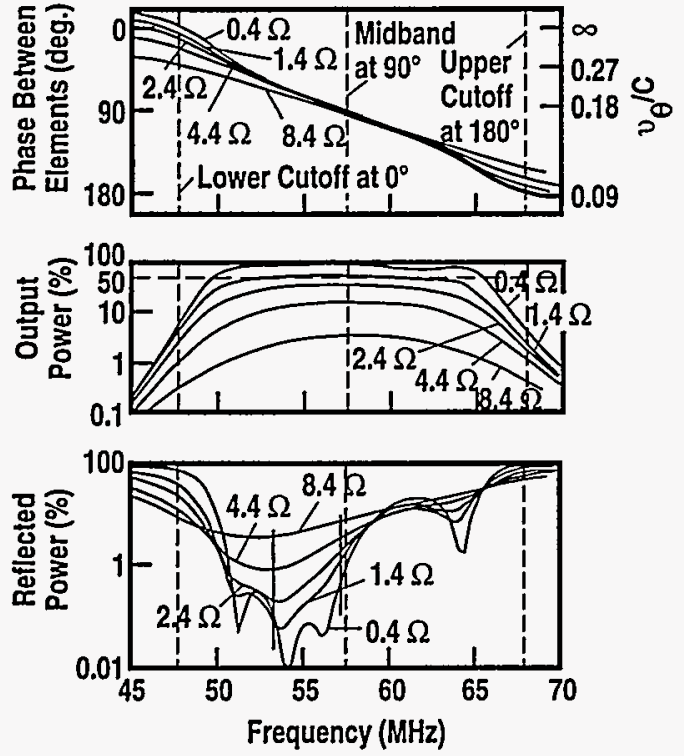

Fig 3. Transmission and reflection characteristics for TWA.

reflected power during ELM-free $\mathrm{H}$-mode. This corresponds to $v_{\theta}, \sim c / 4$ at $54 \mathrm{MHz}$, which is appropriate for advanced operation of DIII-D at $10 \mathrm{keV}$ electron temperature.

For the condition of equal inner and outer element electrical length, the TWA simulation results are consistent with observations made during lower power experiments, wherein the low reflection band occurs toward the high phase end of the passband. To move this band toward the low phase end (as in Fig. 3) the stub-length of the inner two elements in Fig. 1 are made shorter than those of the outer two elements.

\section{CONVERSION OF THE OLDER ANTENNA TO A} TWA FEATURING MULTI-PASS COUPLING TO PLASMA

The efficiency $\eta$ with which power is coupled to the plasma can be represented to a first approximation by

$$
\eta=\frac{4 R_{p}}{R_{t}+4\left(R_{o}+R_{p}\right)}
$$

where $R_{p}$ is the measured plasma resistance and $R_{0}$ represents the ohmic loss to the element-transmission line conductors. For $\mathrm{R}>90 \%$ during ELM-free $\mathrm{H}$-mode $(\mathrm{Rp} \gtrsim$ $1 \Omega$ [17]), the transmissin line must be short enough that $R_{0}<0.1 \Omega$. this makes second harmonic TWA operation of the older antenna attractive.
The new term unique to TWAs is $R_{t}$, corresponding to the uncoupled power appearing at the TWA output. In order to maintain over $90 \%$ coupling efficiency to the plasma during single pass operation, $\mathrm{R}_{\mathrm{t}}$ must not become too large. However, during a single pass the $35 \%$ fractional bandwidth TWA couples $50 \%$ of the power to a $1.4 \Omega \mathrm{load}$, thereby, leaving $50 \%$ uncoupled power at TWA output. To couple $90 \%$ of the power, the plasma load must be increased to about 5 ohms (more typical of ELM loading).

Alternatively, for weaker than $90 \%$ power coupling to the plasma, the uncoupled power appearing at the TWA output can be recovered by connecting it back to the TWA input as shown in Fig. 1. This defines a traveling wave resonant power recirculator. The source power is coupled onto this recirculator in the same direction as the recovered power, using a device called a directional coupler. There are two necessary conditions that both be satisfied for optimum recirculator performance $[7,10]$ :

1) There exists an optimum directional coupling factor for a given power dissipated where all of the input power is coupled to the plasma (plus conductor surfaces) $[7,10]$ When this condition is satisfied almost no power is coupled to the dummy load. This is represented by the dashed curve through the maxima of the family of curves in Fig. 4. Note that the $3 \mathrm{~dB}$ (i.e. 0.7 in amplitude) hybrid coupler deployed in Fig. 1 is optimum when $50 \%$ of the source power is coupled to the plasma. This causes $2 \mathrm{MW}$ traveling wave power to appear at the TWA input and $1 \mathrm{MW}$ at the output.

2) For optimum traveling wave resonance the electrical length around the recirculator circuit in Fig. 1 must be an integral number of wavelengths $[7,10]$. This condition has been experimentally observed using a TWA conversion of the older antenna [10]. For example, a resistive wall placed in front of this TWA created $50 \%$ output power along the plateau of the single pass characteristic identified in Fig. 5. By recirculating this output power through an optimized recirculator, the multi-pass coupling line shape identified in Fig. 5 was observed. The narrow linewidth is caused by the rapid TWA phase shift due to the inherent (5\%) bandwidth of this TWA. By adding coupling inductance to this TWA the $35 \%$ fractional bandwidth of the TWA described in Section III was obtained, the rate of phase change is significantly reduced and the recirculator line width correspondingly broadened, as also shown in Fig. 5 . 


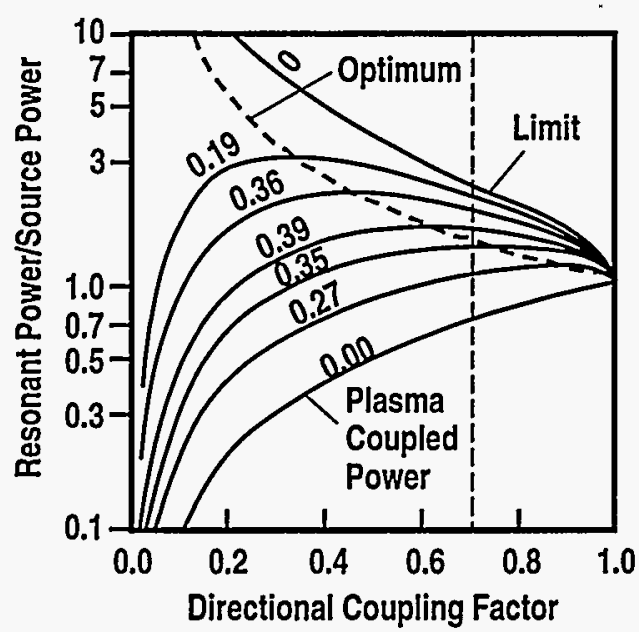

Fig 4. Optimum recirculator directional coupling curves.
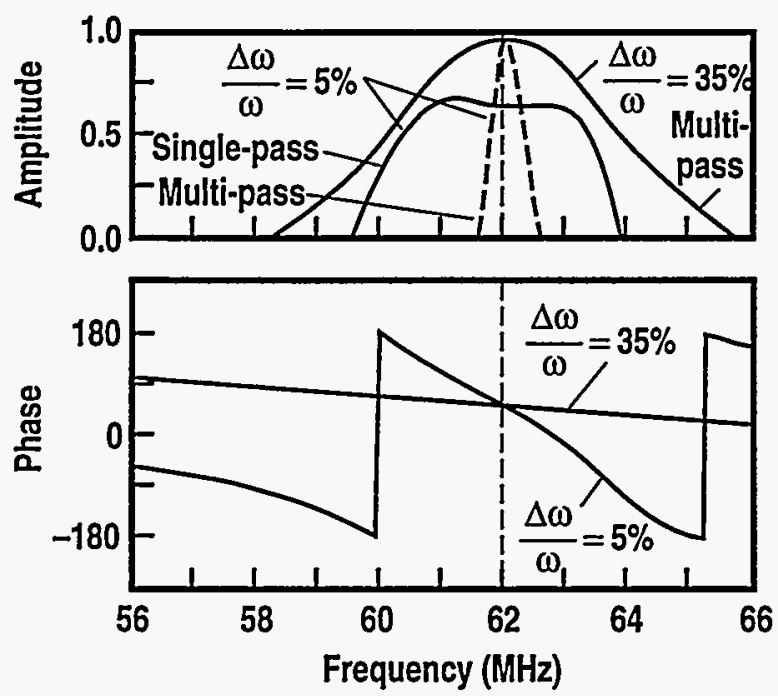

Fig 5. Measured and simulated transmission magnitude and phase.

As a consequence, the predicted $5 \%$ phase change during ELMing $\mathrm{H}$-mode should not appreciably reduce the recirculator coupling efficiency. Any increase in uncoupled power during ELMs is simply dumped to the dummy load. The reflected power remains less than $1 \%$ and the source continues to operate as desired. Nevertheless, frequency feedback control of the low power oscillator can be used to optimize the recirculator phase condition during changing plasma conditions.

\section{v. CONCLUSIONS}

A generic rf circuit for TWA conversions of four element antennas in tokamaks has been described. The salient results of a low power TWA experiment in DIII-D have been presented, in order to validate the important TWA operating conditions for low reflected power, stable structure wave phase velocity, and efficient power coupling to the plasma. Computer simulation predictions for a second harmonic TWA based on detailed empirical modeling and associated electrical parameters have been presented. A TWA with a $35 \%$ fractional bandwidth has been identified that predicts stable operation with $0.1-1 \%$ reflected power and $50 \%$ single pass power coupling efficiency. A recirculator has been proposed to increase the plasma coupled power to over $90 \%$.

\section{REFERENCES}

[1] D.B. Remsen, et al., in Proc. of the 15th Symp. on Fusion Engineering, Hyannis, p. 1088, 1993.

[2] F. Durodie and M. Vervier, in Proc. of the Euro. Top. Conf. on RF Heating and Current Drive of Fusion Devices, Brussels, vol. 16E, p. 81, 1992.

[3] J. Jacquinot, JET, private communication (January 1995).

[4] R.H. Goulding, et al., AIP Conf. Proc. 289, 10th Top. Conf. on RF Power in Plasmas, Boston, p. 351, 1993.

[5] F.W. Baity, et al., AIP Conf. Proc. 289, 10th Top. Conf. RF Power in Plasmas, Boston, p. 343, 1993.

[6] F.W. Baity, et al., in Proc. 16th Symp. on Fusion Technology, p. $1035,1990$.

[7] C.P. Moeller, et al., in Proc. Euro. Top. Conf. on RF Heating and Current Drive of Fusion Devices, Brussels, vol. 16E, p. 53, 1992.

[8] C.P. Moeller, et al., AIP Conf. Proc. 289, 10th Top. Conf. on RF Power in Plasmas, Boston, p. 323, 1993.

[9] D.A. Phelps, et al., Bull. Am. Phy. Soc. 37, p. 1513, 1992.

[10] D.A. Phelps, et al., AIP Conf. Proc. 289, 10th Top. Conf.

[11] D.A. Phelps, et al., Bull. Am. Phys. Soc. 38, 2069 (1993).

[12] D.A. Phelps, et al., Bull. Am. Phys. Soc. 39, 1649 (1994).

[13] D.A. Phelps, et al., in Proc. 11th Top. Conf. on RF Power in Plasmas, Palm Springs (May 17-19, 1995).

[14] H. Ikezi and D.A. Phelps, General Atomics Report GA-A21993, July 1995.

[15] R. Prater, et al., General Atomics Report GA-A22088, July 1995.

[16] R.H. Goulding, et al., Fusion Eng. and Design 24, p. 104, 1994.

[17] M.J. Mayberry, et al., General Atomics Report GA-A19565, 1989. 